\title{
P02.158. Tai Chi community program is effective in reducing elderly fall-related hospital utilization: a prospective observational study
}

E Ziea

From International Research Congress on Integrative Medicine and Health 2012

Portland, Oregon, USA. 15-18 May 2012

\section{Purpose}

Overseas studies and reviews showed that about $30 \%$ of elderly suffer from falls every year and approximately one fall in ten resulted in fractures. Fall is a major cause of hospitalization in Hong Kong, ranking the fifth in terms of total bed days of all public acute hospitals. Tai Chi (TC) is a Chinese martial art form for centuries and seems to be an effective intervention to prevent falls through improving functional balance and physical response.

\section{Methods}

A prospective observational study of 3,222 communitydwelling elderly aged 60 or above was conducted to assess the effect of TC in reducing injurious falls incidence. Participants were community-dwelling elderly aged 60 or above with "Timed Up-and-Go" test (TUGT) less than or equal to 20 seconds. An hour simplified TC session led by recognized TC coaches was performed twice a week in a period of four weeks. Participants were encouraged to practice TC after training. Injurious fall incidents were retrieved and compared from a medical records database 12 months before and after TC training between 2 strata: continue $(n=1,269)$ vs cease $(n=1,360)$ TC in 12 months post training.

\section{Results}

The injurious fall rate dropped from $2.21 \%$ (pre) to $1.34 \%$ (post) in the continuing TC group while the fall rate increased from $2.06 \%$ (pre) to $3.46 \%$ (post) in the noncontinuing TC group. The percentage of hospitalization

\footnotetext{
Chinese Medicine Department, Hospital Authority of Hong Kong, Hong
} Kong, Hong Kong

( 2012 Ziea; licensee BioMed Central Ltd. This is an Open Access article distributed under the terms of the Creative Commons Attribution License (http://creativecommons.org/licenses/by/2.0), which permits unrestricted use, distribution, and reproduction in any medium, provided the original work is properly cited. due to fall-related injuries was $0.39 \%$ and $1.03 \%$ in the continuing and non-continuing TC groups, respectively.

\section{Conclusion}

Study results demonstrate that TC has a potential preventive effect on injurious falls and hospital utilization.

Published: 12 June 2012

doi:10.1186/1472-6882-12-S1-P214

Cite this article as: Ziea: P02.158. Tai Chi community program is effective in reducing elderly fall-related hospital utilization: a prospective observational study. BMC Complementary and Alternative Medicine 2012 12(Suppl 1):P214.

Submit your next manuscript to BioMed Central and take full advantage of:

- Convenient online submission

- Thorough peer review

- No space constraints or color figure charges

- Immediate publication on acceptance

- Inclusion in PubMed, CAS, Scopus and Google Scholar

- Research which is freely available for redistribution
() Biomed Central 